\title{
Dicionário Escolar de Matemática
}

\section{Maria Regina Alfredo Plazza}

mareginapla@hotmail.com

EE Diva Figueiredo da Silveira - Paraguaçu Paulista - SP - Brasil

\section{Resumo}

A nova prática pedagógica exige que a aprendizagem seja democrática, com ações compartilhadas e prazerosas, um professor reflexivo que compreenda o seu papel de mediador e uma escola que acredita $\mathrm{e}$ desenvolve o sucesso do aluno.

Levando em consideração as dificuldades de aprendizagem que os alunos apresentam em relação à compreensão dos enunciados e dos conceitos matemáticos e aos baixos índices apresentados nas avaliações externas (SARESP/ IDEB), percebeu-se a necessidade de criação de uma ferramenta para auxiliar na qualidade do ensino.

A proposta é desenvolver um dicionário escolar de matemática escrito e ilustrado pelos próprios alunos, para ser atraente e despertar o interesse em relação ao universo da matemática. Ele deve apresentar os termos em ordem alfabética e, além de definições de fácil compreensão, trazer ilustrações coloridas e frases curtas que colocam o vocábulo em contexto.

O Dicionário será desenvolvido durante todo 0 ano letivo com os alunos do $6^{\circ}$ ano do Ensino Fundamental sob a orientação das professoras de Matemática e Português e supervisão da Equipe Gestora.

Com o projeto já pronto, espera-se tornar a compreensão da Matemática mais fácil auxiliando na interpretação dos conceitos, melhorando dessa forma os índices nas avaliações e estimulando o interesse pela disciplina.

Palavras-chaves: Educação. Dicionário de matemática. Plano de empreendimento. Inovação pedagógica. 


\section{Identificação da unidade escolar}

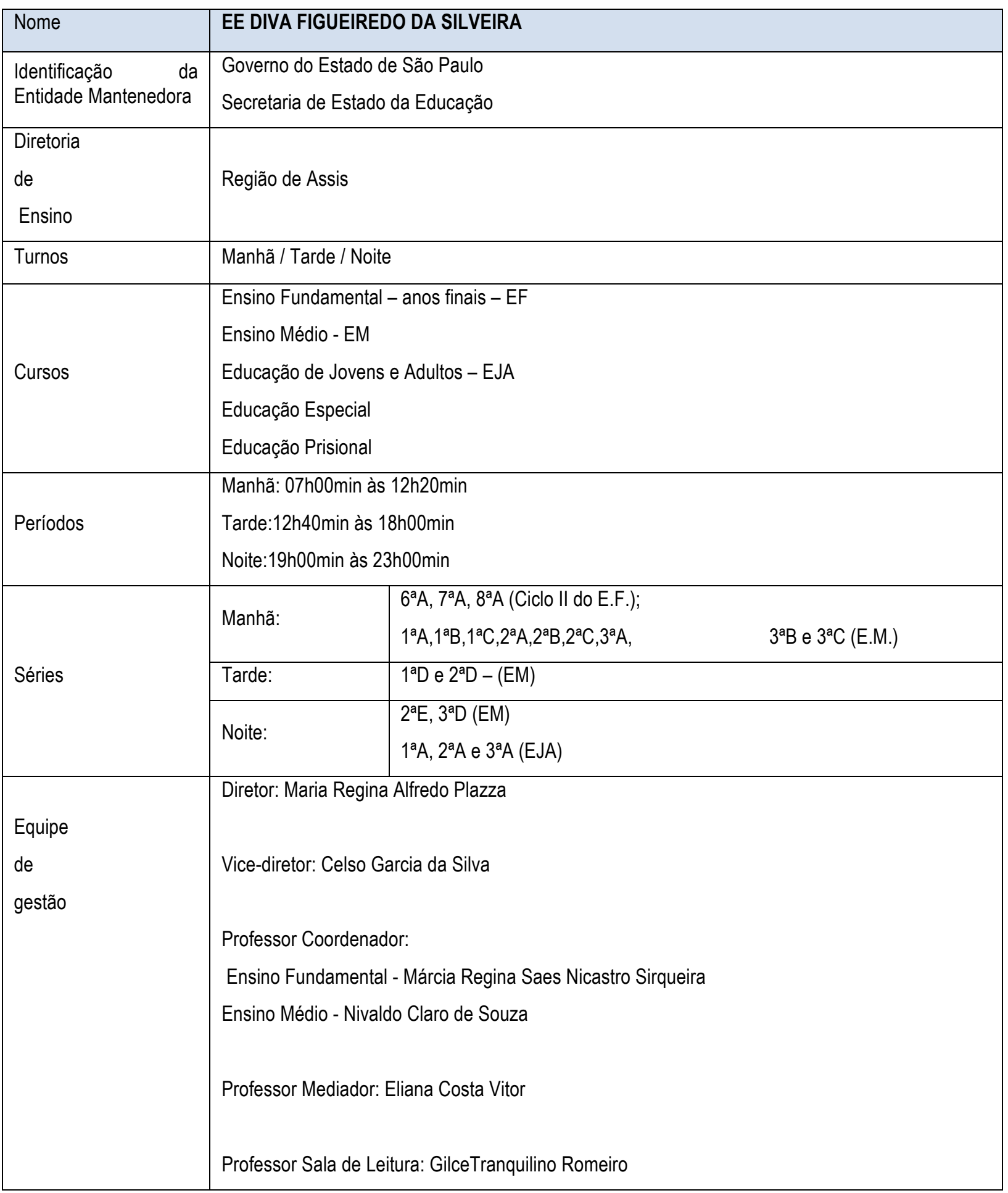




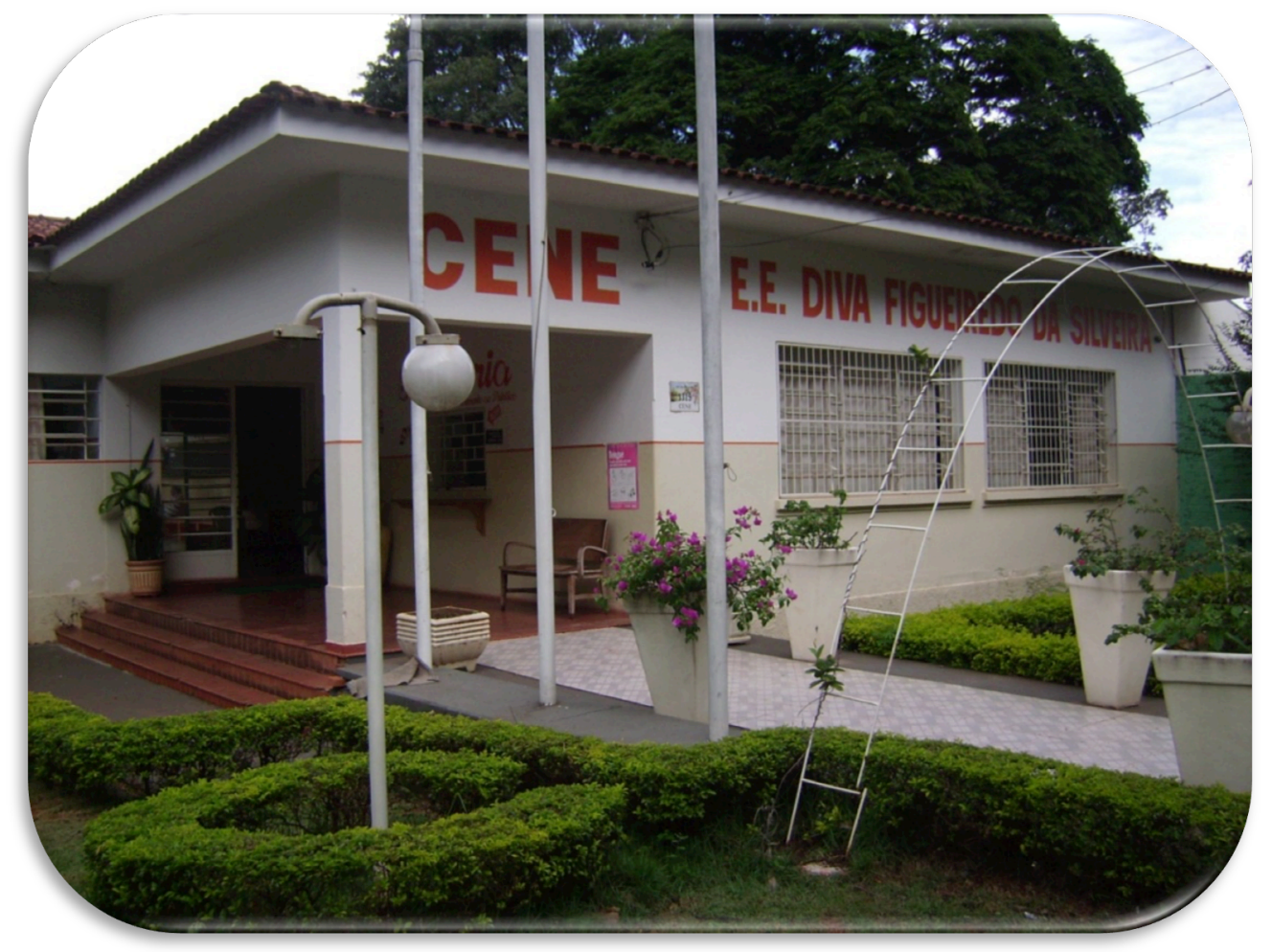

\section{Caracterização da unidade escolar}

\section{Histórico da escola}

A EE Diva Figueiredo da Silveira foi criada pela Lei n075 de 23/02/1948. Sua Instalação se deu a 01/08/1948 e seu funcionamento teve início a 05/08/1949 num prédio de madeira, onde funcionava o $2^{\circ}$ Grupo Escolar.

Hoje a escola tem um prédio agradável e arborizado. Com um pátio bem grande, contém duas quadras poliesportivas e vários ambientes prazerosos, como o jardim dos sentidos, mesinhas embaixo de árvores, anfiteatro, sala de leitura, sala de recursos, sala de informática, sala multimídia, cantina, refeitório, etc. 0 clima relacional apresenta algumas dificuldades e dificulta o desenvolvimento do trabalho coletivo.

\section{IMPORTÂNCIA PARA A COMUNIDADE}

Esta é uma escola tradicional, com grande prestígio e importância perante a comunidade por ter sido uma das primeiras escolas criadas na cidade e grande parte da população mais velha estudou nela. Por localizar-se numa região central, atende jovens de toda a cidade, adultos que retornaram aos estudos e alunos da zona rural.

\section{Clientela}

\section{Perfil dos estudantes}

\section{Alunos do Ensino Fundamental e Médio}

Os alunos do Ensino Fundamental e Médio apresentam problemas semelhantes aos observados na maioria das escolas: alguns são desatentos, sem muita disposição para os estudos, porém se observa a existência de alunos interessados, atentos e cordiais.

A maioria deles pertence a uma classe econômica menos favorecida e muitas destas famílias se preocupam com o progresso dos filhos. 


\section{Alunos do Ensino Médio da EJA}

São alunos que estiveram muito tempo fora da sala de aula, além de chegarem cansados, após um dia repleto de afazeres no trabalho. Nesse processo de retomada muita coisa se perdeu em seus estudos, assim, apresentam dificuldade de acompanhar o currículo proposto em sala de aula.

\section{Alunos da Educação Especial}

São jovens que apresentam necessidade educacional especial, que precisam de acompanhamento individualizado e são provenientes de toda a região, inclusive de municípios vizinhos.

Atualmente, a escola atende um total de 752 alunos distribuídos em três (3) turnos, nas seguintes turmas:

\begin{tabular}{|l|l|l|}
\hline Ano de escolaridade/segmento & No de turmas & No de alunos \\
\hline $6^{0}$ ano / E.F. & 01 & 33 \\
\hline $7^{0}$ ano / E.F. & 01 & 38 \\
\hline $8^{\circ}$ ano / E.F. & 01 & 37 \\
\hline $1^{\circ}$ ano / E.M. & 04 & 137 \\
\hline $2^{\circ}$ ano / E.M. & 05 & 172 \\
\hline $3^{\circ}$ ano / E.M. & 04 & 142 \\
\hline $1^{\circ}$ ano / EJA. & 01 & 31 \\
\hline $2^{\circ}$ ano / EJA & 01 & 28 \\
\hline $3^{\circ}$ ano / EJA & 01 & 32 \\
\hline Ed. Especial DI & 01 & 09 \\
\hline Ed. Especial DF & 01 & 06 \\
\hline Ed. Prisional - EJA & 06 & 87 \\
\hline TOTAL DE TURMAS & 27 & 752 \\
\hline
\end{tabular}

\section{Perfil dos Professores}

O quadro de professores é composto por profissionais especializados, cada qual habilitado em sua disciplina e preparados para o trabalho com crianças, adolescentes e adultos. A maioria dos professores é efetiva na Secretaria Estadual da Educação. Ao ingressar no quadro docente estes profissionais participam de treinamento específico e atividades periódicas de reciclagem que visam não somente garantir a aplicação correta da metodologia e do currículo, mas também o aperfeiçoamento contínuo no que diz respeito aos aspectos pedagógicos e de relacionamento interpessoal. Contam ainda com o apoio didático e a supervisão permanente da Coordenação Pedagógica. Professores pouco motivados por salários baixos e uma rotina estafante.

\section{Perfil da Comunidade}

A comunidade escolar é pouco favorecida no aspecto socioeconômico onde as famílias são de classe média baixa e pobre. É um bairro central onde a maior área de lazer é a própria escola. Já foi um bairro muito tranquilo, mas no momento enfrenta em seu entorno roubos e violências com o agravante do serviço de segurança ser falho. 


\section{Objetivos da escola}

A nova prática pedagógica proposta exige uma escola democrática que tenha muito claro seus objetivos e que promova ações compartilhadas junto a comunidade para o sucesso do aluno, desenvolvendo competências e elevando a qualidade do ensino. Exige também um professor reflexivo, que compreenda 0 seu papel de mediador no processo de construção do conhecimento, e que promova ações didáticas eficazes. Demanda ainda, um currículo que sirva de referência para ampliar, localizar e contextualizar os conhecimentos acumulados pela humanidade ao longo do tempo, representando assim um espaço de cultura.

\section{Definição da missão, visão e valores da escola:}

\section{Missão da Escola:}

A missão é a de sermos uma escola que esteja voltada para formar cidadãos críticos, pensantes e conscientes de seus direitos e deveres, com uma configuração de proposta aberta visando criatividade e criticidade e não o acúmulo de informações. Educar criando condições de acesso ao mundo de trabalho e continuação em estudos posteriores.

\section{Visão da escola:}

A unidade escolar tem como visão educar enfatizando o processo da descoberta e familiarizando o aluno com outras possibilidades que não sejam os conteúdos específicos, aprendendo a ter autoconfiança nas suas observações e nas suas interpretações, fomentando posturas criticas contestadoras, construtivas, solidárias, sustentados pelas características do pensamento científico desenvolvendo dessa forma um sujeito ativo, transformador da sua realidade.

\section{Valores:}

A escola está baseada num conjunto de valores organizacionais dos quais fazem parte sua visão, missão, crença, filosofia e as políticas de gestão. Acreditamos na relação de trabalho baseado em confiança e respeito mútuos e numa liderança aberta ao questionamento responsável.

\section{Indicadores e resultados:}

\section{Resultado final da escola - 2013}

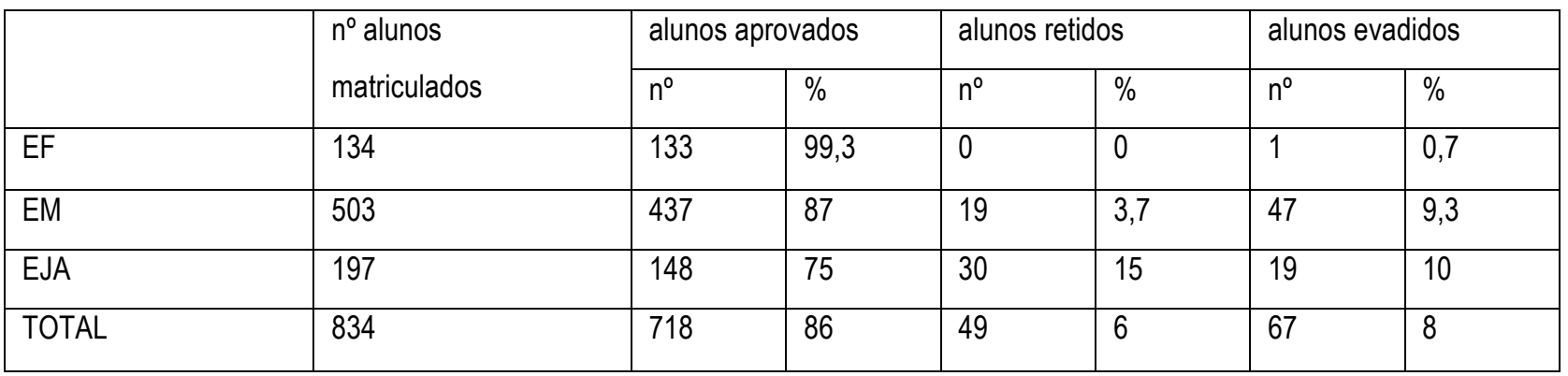

Indicadores da escola - idesp 2013

\begin{tabular}{|l|l|l|l|l|l|}
\hline \multirow{2}{*}{} & \multicolumn{2}{|l|}{ Indicadores de desempenho } & $\begin{array}{l}\text { Indicador de } \\
\text { desempenho }\end{array}$ & Indicador de fluxo & IDESP 2013 \\
\cline { 2 - 3 } & Português & Matemática & & \\
\hline
\end{tabular}




\begin{tabular}{|l|l|l|l|l|l|}
\hline $9^{\circ}$ ano EF & 2,8963 & 2,405 & 2,65 & 0,9925 & 2,63 \\
\hline $3^{\mathrm{a}}$ série EM & 2,2987 & 1,1207 & 1,71 & 0,8705 & 1,49 \\
\hline
\end{tabular}

\section{Identificação do problema ou da oportunidade}

A indisciplina, o baixo rendimento e o descaso são os maiores problemas que as escolas enfrentam nos dias de hoje. Os professores encaram como responsabilidade apenas dos alunos, a escola cobra do professor uma solução e os pais só querem saber do resultado no final do ano.

O aprendizado do aluno e o bom comportamento dele na escola são de responsabilidade de todos: da escola, do professor, da família e do próprio aluno.

A escola deve oferecer recursos como laboratórios, materiais didáticos e normas disciplinares para que 0 professor possa promover suas aulas. Ainda com o apoio da escola, o professor deve estar sempre atento às mudanças e às inovações na educação, para que desenvolva estratégias para ligar o conteúdo aplicado em sala de aula com o dia-a-dia do aluno, tornando o ambiente escolar um lugar prazeroso com domínio de conteúdo, promovendo o protagonismo juvenil e gerando alunos mais confiantes e estudiosos.

A participação da família em conjunto com a escola é importante, mas o professor é o que possui maior possibilidade de transformar e dar soluções para esse tipo de problema, pois está em contato direto com os alunos. É preciso que ele enxergue esse aluno indisciplinado e/ou com dificuldade de aprendizado, como um desafio e não como problema. Ser professor não é derramar conteúdos e cumprir o currículo anual, é educar, participar e colaborar com a educação dos alunos.

Levando em consideração as dificuldades de aprendizagem que os alunos apresentam em relação aos conceitos matemáticos e aos baixos índices apresentados pela escola nas avaliações externas (SARESP/ PROVA BRASIL), percebeu-se a necessidade de criação de uma ferramenta para auxiliar na compreensão dos conceitos, principalmente dos enunciados e assim contribuir para a resolução dos problemas, que são considerados difíceis pelos alunos, mas não pelo cálculo em si e sim pela compreensão de qual estratégia de cálculo é necessário para sua solução.

Segundo Hellmeister:

\section{(...) uma das grandes dificuldades no ensino da Matemática é a linguagem em}

que precisa ser utilizada. Muitas vezes percebemos que os alunos

compreendem a "ideia" mas não são capazes de manipular a linguagem.

Outras vezes, o que é pior, manipulam a linguagem de forma automática sem

aprender seu significado. (HELLMEISTER, 2004, p.7)

A proposta de construção de um Dicionário de matemática nas aulas de Matemática e Português, no ano de 2006, onde eu, na época professora de matemática de uma $5^{\mathrm{a}}$ série do Ensino Fundamental, num trabalho interdisciplinar juntamente com a professora de português da turma, foi desenvolvida com muito sucesso. 0 projeto foi recebido com surpresa pelos alunos, pois estes tinham o entendimento de que nas aulas de Matemática apenas deveriam aprender a fazer contas.

Porém, a construção do dicionário contribuiu para a compreensão do significado de cada palavra, pois os alunos se empenharam na organização, tanto na busca do significado correto para cada conceito quanto em reescrever este significado através de uma linguagem pessoal, de uma forma que o tornasse mais fácil de ser compreendido. Os alunos pesquisaram o significado dos conceitos, reescreveram através de uma linguagem mais simples e ilustraram, facilitando a compreensão e entendimento dos conceitos e possibilitando aos alunos criar relação entre as duas disciplinas em questão percebendo que a Matemática não é uma ciência 
isolada, desconexa das demais, mas que possui relação com as demais disciplinas, desmistificando a compreensão da Matemática como sendo uma disciplina apenas de rigor, mas que envolve muito mais que fazer contas.

O projeto além de levar os alunos a desenvolver as habilidades de pesquisa, inferência, compreensão, discussão e construção dos significados das palavras nos seus diversos contextos, também propiciou a troca de informações, criando situações de favorecimento ao desenvolvimento da sociabilidade, da cooperação e do respeito mútuo entre os alunos.

Com o projeto já pronto, percebeu-se que o dicionário estava auxiliando na compreensão dos conceitos, no desenvolvimento dos conteúdos matemáticos, na leitura e interpretação dos problemas, melhorando assim 0 desenvolvimento dos alunos que, além dos resultados terem sido alcançados, passaram a ter mais interesse pela disciplina, tornando a resistência de aprendizagem do aluno pela matéria um pouco menor.

O projeto desenvolvido obteve grandes resultados na época. Em 2009, os alunos participantes fizeram as avaliações externas do SARESP da antiga $8^{a}$ série que hoje representa $09^{\circ}$ ano do Ensino Fundamental e foi o maior índice apresentado em matemática nos últimos anos. Além disso, esta classe que encerrou o Ensino Médio em 2012, inseriu nas universidades cinco alunos cursando Licenciatura de matemática.

\section{Indicadores da escola - IDESP 2009 e 2013}

\begin{tabular}{|l|l|l|}
\hline \multirow{2}{*}{} & Indicadores de desempenho \\
\cline { 2 - 3 } & Português & Matemática \\
\hline $8^{\mathrm{a}}$ série EF -2009 & 2,62 & 3,91 \\
\hline $9^{0}$ ano EF- 2013 & 2,8963 & 2,405 \\
\hline
\end{tabular}

Hoje, em 2014, me encontro na condição de Diretora da escola e me deparo com um índice IDESP muito baixo em matemática. Para contribuir para um melhor entendimento dos conceitos trabalhados durante as aulas de Matemática, incentivar e promover o trabalho em equipe e a cooperação entre os alunos, auxiliar na apropriação de conceitos matemáticos e tornar as aulas mais interessantes e atraentes, propus aos professores de Português e Matemática do $6^{\circ}$ ano que desenvolvessem este mesmo projeto e ambos não só concordaram como já estão se empenhando para que ele aconteça neste ano de 2014.

\section{Caracterização do produto/serviço e/ou processo}

A proposta é desenvolver um Dicionário Escolar de Matemática escrito e ilustrado pelos próprios alunos. 0 objetivo é despertar o interesse em relação ao universo da matemática e tornar a aprendizagem atraente e motivadora. Ele deve apresentar os termos em ordem alfabética e, além de definições de fácil compreensão, trazer ilustrações coloridas e frases curtas que colocam o vocábulo em contexto. Os termos deverão estar de acordo com os conteúdos estudados no Ensino Fundamental e escolhidos para apoiar e desenvolver a linguagem matemática facilitando a compreensão dos conceitos, podendo assim ser adotado como apoio a qualquer fase escolar.

O Dicionário será desenvolvido em duas fases: no $1^{0}$ semestre pretende-se realizar a busca de parceiros e orientação aos alunos e pais. $02^{\circ}$ semestre será destinado ao trabalho de pesquisa, de aprendizado dos conteúdos e à confecção do dicionário com os alunos do $6^{\circ}$ ano do Ensino Fundamental, sob a orientação das professoras de matemática e português da turma. A professora Coordenadora Pedagógica subsidiará os trabalhos desenvolvidos dentro e fora da sala de aula.

\section{0 desenvolvimento do projeto terá as seguintes etapas:}

Explanação acerca do tema proposto pelas professoras envolvidas ( $1^{\circ}$ semestre);

Busca de parceiros para os custos $\left(1^{\circ}\right.$ semestre); 
Distribuição de livros didáticos diversificados de Ensino Fundamental de matemática para levantamento dos termos desconhecidos pelos alunos (agosto);

Formação dos grupos (agosto);

Digitação de todos os termos encontrados e organização destes em ordem alfabética, na Sala de Informática (agosto);

Divisão dos termos nos diferentes grupos (setembro);

Desenvolvimento das habilidades de pesquisa, inferência e compreensão, através da discussão e construção dos significados das palavras nos seus diferentes contextos, e em especial, nos conceitos de matemática (setembro/outubro);

Retorno à sala de informática para digitação dos termos e seus significados e ilustração dos vocábulos (setembro/outubro);

Organização do material para a encadernação: um dicionário para cada participante do projeto (novembro);

Lançamento do Dicionário Escolar de Matemática (dezembro).

A metodologia do projeto terá o intuito de desenvolver nos alunos as habilidades de leitura, pesquisa, inferência e compreensão na construção de seu próprio conhecimento utilizando as diversas ferramentas como computadores, internet, livros, dicionários, etc.

\section{A avaliação será concomitante com o desenvolvimento do trabalho considerando alguns critérios:}

Organização dos grupos e envolvimento de cada membro;

Cumprimento das etapas (tarefas) e envolvimento de cada membro;

Aspectos visuais do trabalho;

Produção do texto;

Produção da capa.

Concluindo a proposta, este projeto tem tudo para dar certo, haja vista que já foi um projeto desenvolvido nesta mesma escola e que foi um sucesso de aprendizagem, de interesse e de índices nas avaliações externas.

Os alunos terão o privilégio de protagonizar a aprendizagem dos conteúdos propostos e de produzir seu próprio material didático para utilização durante todo o curso do Ensino Fundamental, criando assim um suporte que servirá de subsídio em toda a sua trajetória escolar.

Tornar os parceiros das custas do projeto uma constante para que as futuras sextas séries possam usufruir deste aprendizado também.

E finalmente esclarecer que a preocupação inicial é que haja interesse e envolvimento dos alunos no projeto, mas à medida que o trabalho for sendo elaborado, que eles mesmos encontrem as soluções e os caminhos para a realização de um trabalho de um bom nível e com excelente visual, desenvolvendo assim a aprendizagem e 0 amadurecimento na elaboração de trabalhos acadêmicos.

\section{Estratégia de implementação}

A proposição das estratégias se deu de forma clara e organizada. Montamos os grupos para a organização dos espaços e locação dos muros da escola para o comércio local. Com o objetivo de suprir todas as despesas e custas do projeto a locação se deu de forma tranquila e transparente através de contrato firmado com a APM da escola. Todos os professores da classe ( $6^{\circ}$ ano do Ensino Fundamental) se envolveram e por ser um local estratégico, conseguimos locar todos os espaços até o início das férias (12 de junho).

As professoras de matemática e português se organizaram para dar início ao projeto no $2^{\circ}$ semestre. 
Organizaram uma reunião (maio) com os pais e/ou responsáveis juntamente com os alunos para orientá-los sobre a importância que este projeto terá na vida escolar deles e da necessidade do comprometimento de todos. Em sala de aula as professoras conversaram e motivaram os alunos para que a ideia desta construção de conhecimento desenvolvido por eles seja uma atividade prazerosa e de sucesso.

A equipe gestora encontra-se com todos os membros envolvidos no projeto apoiando e colaborando com a organização dos espaços e materiais necessários ao melhor desenvolvimento do projeto.

Os responsáveis pela sala de leitura e sala de informática também se organizaram e estão preparados para as aulas que acontecerão no local.

Fizemos o levantamento das forças, fraquezas, oportunidades e ameaças que podem interferir no desenvolvimento do projeto para definirmos a melhor estratégia, ficando assim esquematizada:

\section{Análise SWOT}

\begin{tabular}{|c|c|}
\hline Forças & Fraquezas \\
\hline $\begin{array}{l}\text { Formação contínua dos educadores, durante as ATPCs; } \\
\text { Equipamentos em bom estado de conservação na escola; } \\
\text { Participação da comunidade escolar em reuniões e } \\
\text { conselhos; } \\
\text { Integração entre os diversos membros da escola; } \\
\text { Inclusão social e democratização do espaço escolar; } \\
\text { Maior Interesse e participação dos alunos; } \\
\text { Gestão participativa e organizada. }\end{array}$ & $\begin{array}{l}\text { Medo de não alcançar os objetivos exigidos pela SEE; } \\
\text { Resistência de alguns docentes e de funcionários por falta de } \\
\text { comprometimento; } \\
\text { Degradação das instalações físicas. }\end{array}$ \\
\hline Oportunidades & Ameaças \\
\hline $\begin{array}{l}\text { Capacitação em serviço a todos os envolvidos com a } \\
\text { educação; } \\
\text { Valorização do ambiente escolar através de verbas } \\
\text { estaduais; } \\
\text { Materiais pedagógicos atualizados; } \\
\text { Laboratórios diversos; } \\
\text { Participação da comunidade escolar em eventos } \\
\text { promovidos pela escola. }\end{array}$ & $\begin{array}{l}\text { Desinteresse da família dos alunos em participar de ações } \\
\text { dentro da Escola, bem como, falhas em atitudes educativas } \\
\text { junto aos filhos, o que mostra a transferência de } \\
\text { responsabilidade concebida aos professores e diretores; } \\
\text { Marginalidade, violência e falta de segurança; } \\
\text { Vulnerabilidade social. }\end{array}$ \\
\hline
\end{tabular}

Em seguida, definimos as estratégias e os recursos necessários para o desenvolvimento do projeto:

Definição das estratégias
\begin{tabular}{|l|l|l|}
\hline Objetivos & Metas & Estratégias \\
\hline
\end{tabular}




\begin{tabular}{|c|c|c|c|}
\hline $\begin{array}{l}\text { Buscar parceiros para o } \\
\text { projeto "Dicionário } \\
\text { Escolar de } \\
\text { matemática"desenvolvid } \\
0 \text { com o } 6^{\circ} \text { ano do EF. }\end{array}$ & $\begin{array}{l}\text { Conseguir } 100 \% \text { da verba a ser } \\
\text { utilizada até dezembro. }\end{array}$ & \multicolumn{2}{|c|}{$\begin{array}{l}\text { Locar os diferentes pedaços do muro da escola } \\
\text { que se encontra em local estratégico na cidade } \\
\text { para o comércio local de modo a ser um projeto } \\
\text { contínuo em todos os anos. }\end{array}$} \\
\hline $\begin{array}{l}\text { Desenvolver uma forma } \\
\text { diferente de acessar } 0 \\
\text { conhecimento. }\end{array}$ & $\begin{array}{l}\text { Construir um dicionário de } \\
\text { matemática ilustrado no prazo } \\
\text { de } 08 \text { meses (maio a dezembro) }\end{array}$ & \multicolumn{2}{|c|}{$\begin{array}{l}\text { O aluno será capaz de construir seu próprio } \\
\text { conhecimento através dos diferentes campos de } \\
\text { pesquisa e aprendizado oferecidos pela escola: } \\
\text { sala de leitura, sala de informática e outros, com } \\
\text { acompanhamento e orientação contínua } \\
\text { desenvolvida pelas professoras de matemática e } \\
\text { português. }\end{array}$} \\
\hline $\begin{array}{l}\text { Aumentar o interesse e } \\
0 \text { conhecimento dos } \\
\text { alunos pelas diferentes } \\
\text { disciplinas do Ensino } \\
\text { Fundamental e, em } \\
\text { especial, a matemática. }\end{array}$ & $\begin{array}{l}\text { Aumentar em } 60 \% \text { os índices de } \\
\text { desempenho em matemática } \\
\text { nas avaliações externas } \\
\text { (SARESP). }\end{array}$ & \multicolumn{2}{|c|}{$\begin{array}{l}\text { 1.Utilizar o protagonismo juvenil para fazer o } \\
\text { levantamento dos termos técnicos e conceitos da } \\
\text { matemática e reescrevê-los de forma clara e } \\
\text { ilustrada desenvolvendo assim as habilidades de } \\
\text { pesquisa, inferência e compreensão. } \\
\text { 2.Ter um novo material didático para utilizar ao } \\
\text { longo de seus estudos no EF para sanar as } \\
\text { dificuldades encontradas nas resoluções de } \\
\text { problemas. } \\
\text { 3. Eliminar as lacunas de aprendizagem. }\end{array}$} \\
\hline \multicolumn{4}{|l|}{ Recursos necessários } \\
\hline O que vou precisar & Descrição & & Como obter \\
\hline Sulfite e cartucho & $\begin{array}{l}\text { Impressões de atividades dese } \\
\text { em pesquisas na sala de informe } \\
\text { posterior organização na sala de }\end{array}$ & $\begin{array}{l}\text { nvolvidas } \\
\text { tica para } \\
\text { aula. }\end{array}$ & $\begin{array}{l}\text { Recursos obtidos via contrato de } \\
\text { locação APM/comércio de parte do } \\
\text { muro da escola para propaganda. }\end{array}$ \\
\hline $\begin{array}{l}\text { Trabalho de impressão } \\
\text { de gráfica }\end{array}$ & $\begin{array}{l}\text { Impressão do dicionário es } \\
\text { matemática após o resultado final }\end{array}$ & olar de & $\begin{array}{l}\text { Recursos obtidos via contrato de } \\
\text { locação APM/comércio de parte do } \\
\text { muro da escola para propaganda. }\end{array}$ \\
\hline Encadernação & $\begin{array}{l}\text { Capa dura para os dicionários } \\
\text { trabalho da gráfica }\end{array}$ & após 0 & $\begin{array}{l}\text { Recursos obtidos via contrato de } \\
\text { locação APM/comércio de parte do } \\
\text { muro da escola para propaganda. }\end{array}$ \\
\hline
\end{tabular}




\begin{tabular}{|l|l|l|}
\hline & & \\
\hline $\begin{array}{l}\text { Lançamento } \\
\text { Dicionário }\end{array}$ & $\begin{array}{l}\text { Mostrar o trabalho desenvolvido pelos } \\
\text { alunos e professores, valorizando a troca } \\
\text { de conhecimentos e melhorando o } \\
\text { relacionamento entre eles. }\end{array}$ & $\begin{array}{l}\text { Recursos obtidos via contrato de } \\
\text { locação APM/comércio de parte do } \\
\text { muro da escola para propaganda. }\end{array}$ \\
\hline
\end{tabular}

Estabelecemos então os indicadores para o acompanhamento do projeto:

\begin{tabular}{|c|c|c|c|c|c|}
\hline $\mathbf{N}^{0}$ & O QUE? & POR QUE? & ONDE? & QUEM? & QUANDO? \\
\hline 1 & Explanação do projeto & Envolvimento de todos & $\begin{array}{l}\text { Anfiteatro da } \\
\text { Escola }\end{array}$ & $\begin{array}{l}\text { Professores e } \\
\text { alunos do } 6^{\circ} \text { ano, } \\
\text { funcionários } \\
\text { envolvidos }\end{array}$ & Maio/2014 \\
\hline 2 & $\begin{array}{l}\text { Busca de parceiros } \\
\text { para os custos }\end{array}$ & $\begin{array}{l}\text { Levantamento dos } \\
\text { recursos }\end{array}$ & $\begin{array}{l}\text { Visita ao } \\
\text { comércio local. }\end{array}$ & $\begin{array}{l}\text { Professores do } 6^{0} \\
\text { ano, equipe } \\
\text { gestora e membros } \\
\text { da APM }\end{array}$ & $1^{\circ}$ semestre de 2014 \\
\hline 3 & $\begin{array}{l}\text { Levantamento dos } \\
\text { termos e conceitos } \\
\text { matemáticos }\end{array}$ & $\begin{array}{l}\text { Objeto de pesquisa e } \\
\text { aprendizagem dos } \\
\text { alunos }\end{array}$ & $\begin{array}{l}\text { Sala de aula e } \\
\text { sala de leitura. }\end{array}$ & $\begin{array}{l}\text { Professores de } \\
\text { matemática } \quad \text { e } \\
\text { português e alunos } \\
\text { do } 6^{\circ} \text { ano }\end{array}$ & $\begin{array}{l}\text { A partir de agosto de } \\
2014 \text {. }\end{array}$ \\
\hline 4 & $\begin{array}{l}\text { Preparo das listas dos } \\
\text { termos na sala de } \\
\text { informática }\end{array}$ & $\begin{array}{l}\text { Aprendizagem } \\
\text { diferenciada e alunos } \\
\text { aprendendo a aprender } \\
\text { sozinhos. }\end{array}$ & $\begin{array}{ll}\text { Sala } & \text { de } \\
\text { informática } & \end{array}$ & $\begin{array}{l}\text { Funcionário } \\
\text { responsável pela } \\
\text { sala de } \\
\text { informática, } \\
\text { professor-alunos. }\end{array}$ & Agosto/14. \\
\hline 5 & $\begin{array}{l}\text { Construção dos } \\
\text { conceitos pelos alunos }\end{array}$ & $\begin{array}{lr}\text { Montagem do } \\
\text { dicionário para maior } \\
\text { entendimento dos } \\
\text { conceitos matemáticos }\end{array}$ & $\begin{array}{l}\text { Sala de aula e } \\
\text { sala de leitura. }\end{array}$ & $\begin{array}{lr}\text { Alunos } & \mathrm{e} \\
\text { professores } & \text { de } \\
\text { português } & \mathrm{e} \\
\text { matemática } & \end{array}$ & $\begin{array}{l}\text { Setembro } \\
\text { outubro/14. }\end{array}$ \\
\hline 6 & $\begin{array}{l}\text { Digitação dos termos e } \\
\text { seus significados e } \\
\text { ilustração }\end{array}$ & $\begin{array}{l}\text { Consolidação } \quad \text { da } \\
\text { aprendizagem e sua } \\
\text { ilustração para melhor } \\
\text { entendimento. }\end{array}$ & $\begin{array}{ll}\text { Sala } & \text { de } \\
\text { informática } & \end{array}$ & $\begin{array}{lr}\text { Alunos } & \mathrm{e} \\
\text { professores } & \text { de } \\
\text { matemática } & \text { e/ou } \\
\text { português. } & \end{array}$ & $\begin{array}{l}\text { Setembro } \\
\text { outrubro/14. }\end{array}$ \\
\hline 7 & $\begin{array}{lr}\text { Organização } & \text { do } \\
\text { material para a } \\
\text { encadernação }\end{array}$ & $\begin{array}{l}\text { Organização para a } \\
\text { impressão. }\end{array}$ & $\begin{array}{l}\text { Sala de aula e } \\
\text { sala } \\
\text { informática }\end{array}$ & $\begin{array}{lr}\text { Alunos } & \mathrm{e} \\
\text { professores } & \text { de } \\
\text { matemática } & \text { e/ou } \\
\text { português } & \end{array}$ & Novembro/14 \\
\hline 8 & $\begin{array}{lr}\text { Lançamento } & \text { do } \\
\text { Dicionário Escolar } & \text { de } \\
\text { Matemática para a } & \text { a } \\
\text { comunidade } & \end{array}$ & $\begin{array}{l}\text { Divulgação do trabalho } \\
\text { desenvolvido e sua } \\
\text { importância. }\end{array}$ & $\begin{array}{l}\text { Anfiteatro } \\
\text { Escola. }\end{array}$ & $\begin{array}{l}\text { Toda } \\
\text { comunidade } \\
\text { escolar. }\end{array}$ & Dezembro/14 \\
\hline
\end{tabular}




\section{Acompanhamento e controle do desenvolvimento Projeto}

Ao final de cada bimestre serão realizadas reuniões com as professoras envolvidas, com os alunos e com a equipe gestora para analisar e avaliar os resultados do projeto a partir dos registros feitos ao longo do seu desenvolvimento. Para esse acompanhamento será verificado se cada etapa tem sido cumprida dentro dos prazos estabelecidos e se as atividades propostas atingiram os objetivos do projeto. Avaliar junto aos envolvidos se o funcionamento das salas de leitura, sala de informática e demais dependências da escola de uso comum tem ajudado e colaborado para o sucesso do projeto. Verificar ainda junto aos demais professores do $6^{\circ}$ ano, durante o Conselho de Classe/Série, se os alunos estão conseguindo melhorar seus resultados nas diversas disciplinas da matriz curricular, assim como os demais problemas que poderão surgir ao longo do desenvolvimento do projeto.

\section{Marketing e comunicação}

Para a implantação do Projeto "Dicionário Escolar de Matemática" em nossa escola, não tivemos muitos problemas, pelo contrário, tivemos vários motivos para desenvolvê-lo. São eles:

Um projeto que já foi desenvolvido pela escola e obteve um sucesso muito grande com a aprendizagem, com o futuro dos alunos e os índices das avaliações externas;

A escola se encontra numa localização privilegiada. É cercada por um muro muito grande que o comércio local usa para fazer sua propaganda e não é difícil conseguir os recursos necessários para o projeto;

A escola possui uma sala de informática com 15 computadores e todos em funcionamento, podendo ser tranquilamente utilizado pelos professores como uma sala de aula, além de contar com um funcionário responsável para ampará-los;

A escola tem uma sala de leitura com um arquivo bem grande, diferenciado e organizado. Conta ainda com três professoras responsáveis e comprometidas em ajudar nos projetos e nas aulas desenvolvidas nas escolas.

E finalmente as duas professoras de português e matemática do $6^{\circ}$ ano quando souberam do projeto ficaram felizes em poder desenvolver um trabalho diferente, inovador e com qualidade.

Feito isto, convidamos, através de bilhete encaminhado pelos próprios alunos, os pais de alunos e alunos para reunião que ocorreu no anfiteatro da escola. A reunião que tinha por objetivo motivar, esclarecer e buscar o comprometimento de todos foi um sucesso porque conseguimos a adesão de $100 \%$ da participação.

Os pais e alunos que se ausentaram da reunião, a coordenadora pedagógica se incumbiu de telefonar para cada um e chamá-los para que houvesse o comprometimento de todos e teve sucesso com todos os pais e alunos. $O$ interesse foi geral.

Só depois de toda essa análise, foi que a equipe de professores e coordenadores organizou-se para os esquemas de trabalho e distribuição das tarefas.

Até o presente momento, as etapas estão fluindo muito bem. Já conseguimos o dinheiro do projeto através da locação dos muros, os alunos respeitam os combinados, colegas e professores e finalmente percebe-se na escola um clima agradável e de tranquilidade. 


\section{Organização e gerência do empreendimento}

\section{Perfil e experiência da equipe gestora}

\begin{tabular}{|c|c|c|c|}
\hline NOME & FUNÇÃO & $\begin{array}{l}\text { FORMAÇÃO E } \\
\text { EXPERIÊNCIA }\end{array}$ & $\begin{array}{l}\text { PRINCIPAIS ATIVIDADES } \\
\text { (NO PROJETO) }\end{array}$ \\
\hline $\begin{array}{l}\text { Maria Regina } \\
\text { Alfredo Plazza }\end{array}$ & Diretora da Escola & 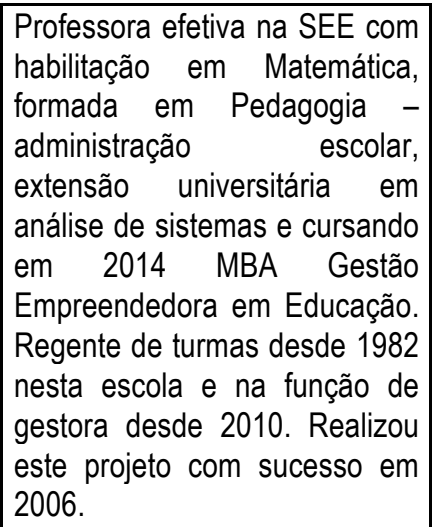 & $\begin{array}{l}\text { Gestora responsável pela tomada } \\
\text { de preços, orçamentos e } \\
\text { prestação de contas das verbas } \\
\text { do projeto. } \\
\text { Responsável por gerenciar na } \\
\text { escola a organização dos } \\
\text { espaços utilizados no projeto. } \\
\text { Planejar e organizar o } \\
\text { lançamento do dicionário à } \\
\text { comunidade escolar. }\end{array}$ \\
\hline
\end{tabular}

\begin{tabular}{|c|c|c|c|}
\hline $\begin{array}{l}\text { Márcia Regina Saes } \\
\text { Nicastro Sirqueira }\end{array}$ & $\begin{array}{l}\text { Professora Coordenadora } \\
\text { Pedagógica - Ensino } \\
\text { Fundamental }\end{array}$ & $\begin{array}{l}\text { Professora efetiva na SEE } \\
\text { formada em Letras, cursando } \\
\text { Gestão Escolar, regente de } \\
\text { turma desde } 1998 \text { nesta escola } \\
\text { e na função de Professora } \\
\text { Coordenadora Pedagógica } \\
\text { desde 2012. Desenvolveu este } \\
\text { mesmo projeto de dicionário em } \\
2006 \text {. }\end{array}$ & $\begin{array}{l}\text { Subsidiar os trabalhos das } \\
\text { professoras responsáveis pelo } \\
\text { desenvolvimento do projeto; } \\
\text { Elaborar os horários de uso da } \\
\text { sala de informática e da sala de } \\
\text { leitura pelos professores e alunos } \\
\text { do projeto. } \\
\text { Marcar as reuniões de divulgação } \\
\text { do projeto junto aos alunos, } \\
\text { professores e pais. } \\
\text { Planejar e organizar o } \\
\text { lançamento do dicionário à } \\
\text { comunidade escolar. }\end{array}$ \\
\hline
\end{tabular}


Perfil e experiência das professoras

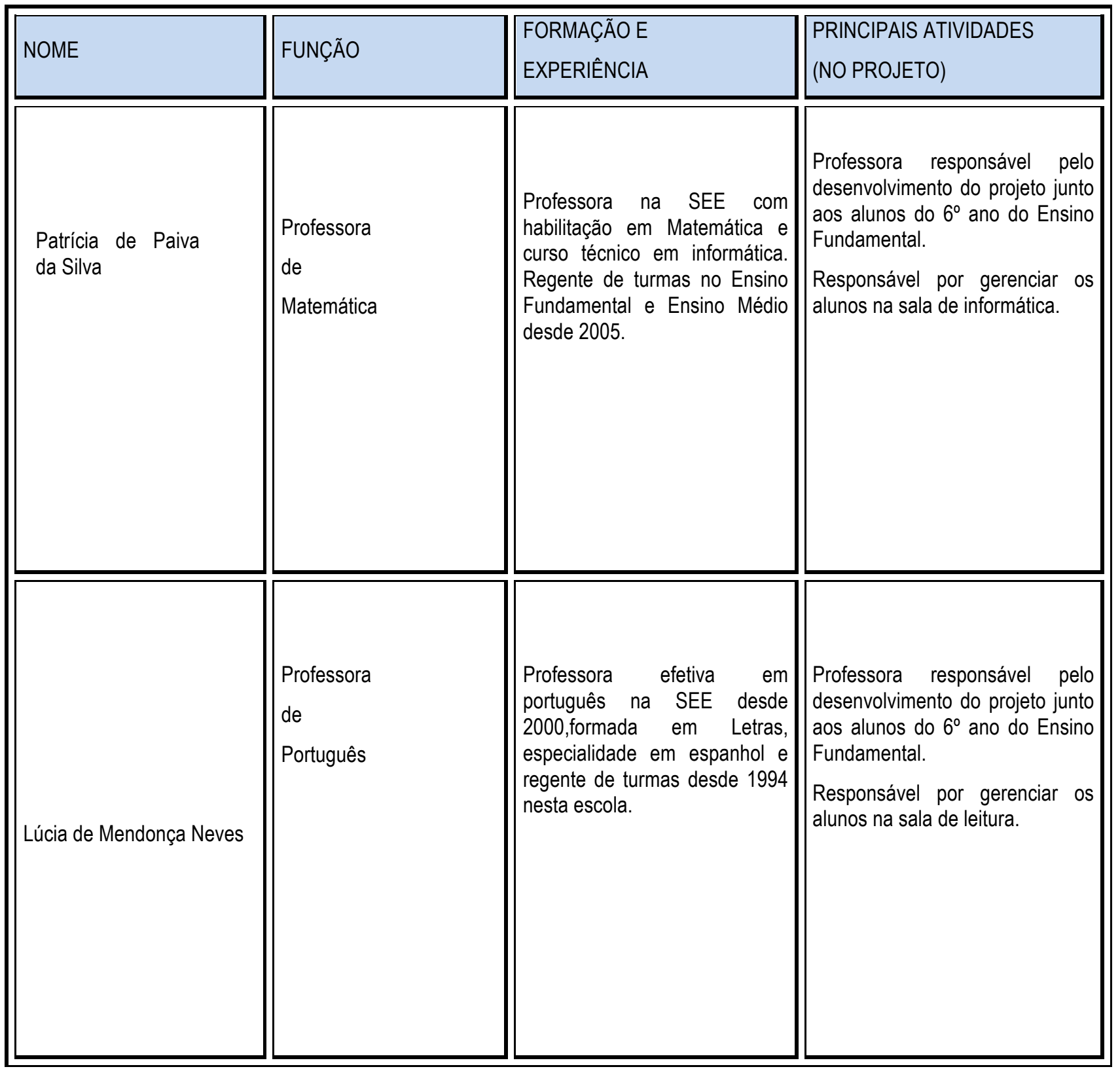

\section{Principais processos}

A tabela a seguir, mostra o perfil da equipe e os principais processos de trabalho necessários para a realização do empreendimento: 


\begin{tabular}{|c|c|c|}
\hline $\begin{array}{ll}\text { PROCESSOS } & \text { DO } \\
\text { EMPREENDIMENTO } & \end{array}$ & COLABORADOR & PERFIL NECESSÁRIO \\
\hline $\begin{array}{l}\text { Divulgação do projeto junto aos } \\
\text { alunos }\end{array}$ & $\begin{array}{l}\text { Professora Patrícia de Paiva da } \\
\text { Silva } \\
\text { e } \\
\text { Professora Lúcia de Mendonça } \\
\text { Neves }\end{array}$ & $\begin{array}{l}\text { Bom relacionamento e respeito com } \\
\text { os alunos. } \\
\text { Experiência no uso das novas } \\
\text { tecnologias aliada a matemática e } \\
\text { português. } \\
\text { Comprometimento com a educação. }\end{array}$ \\
\hline $\begin{array}{l}\text { Divulgação junto aos professores e } \\
\text { pais de alunos. }\end{array}$ & $\begin{array}{l}\text { Diretora Maria Regina Alfredo } \\
\text { Plazza } \\
\text { e } \\
\text { Professora coordenadora Márcia } \\
\text { Regina Saes Nicastro Sirqueira }\end{array}$ & $\begin{array}{l}\text { Bom relacionamento e boa } \\
\text { comunicação verbal. } \\
\text { Reconhecimento da Comunidade } \\
\text { pelos trabalhos e projetos que } \\
\text { desenvolvem na Escola. }\end{array}$ \\
\hline $\begin{array}{l}\text { Venda dos espaços do muro da } \\
\text { escola para divulgação do comércio } \\
\text { local e arrecadação de dinheiro para } \\
\text { o projeto. }\end{array}$ & $\begin{array}{l}\text { Todos os professores do } 6^{\circ} \text { ano do } \\
\text { Ensino Fundamental } \\
\text { e } \\
\text { Equipe Gestora }\end{array}$ & $\begin{array}{l}\text { Equipe de professores com bom } \\
\text { relacionamento na comunidade } \\
\text { local. }\end{array}$ \\
\hline $\begin{array}{l}\text { Coordenação e acompanhamento } \\
\text { do projeto }\end{array}$ & $\begin{array}{l}\text { Márcia Regina Saes Nicastro } \\
\text { Sirqueira }\end{array}$ & $\begin{array}{l}\text { Professora } \\
\text { Coordenadora } \\
\text { Pedagógica com disponibilidade de } \\
\text { tempo na escola, bom } \\
\text { relacionamento com os alunos e } \\
\text { professores e experiência no } \\
\text { projeto. }\end{array}$ \\
\hline $\begin{array}{l}\text { Responsável por adquirir os } \\
\text { materiais, as encadernações e o } \\
\text { lançamento do dicionário. }\end{array}$ & Maria Regina Alfredo Plazza & $\begin{array}{l}\text { Diretora da escola com credibilidade } \\
\text { perante a comunidade local e } \\
\text { responsável pela prestação de } \\
\text { contas da escola. }\end{array}$ \\
\hline
\end{tabular}

\section{PLANO FINANCEIRO}

\section{Investimento (despesa de capital)}

\begin{tabular}{|l|l|l|l|l|}
\hline Investimentos (despesas de capital) & Dezembro \\
\hline Item & $1^{0}$ semestre & $\begin{array}{l}\text { Agosto/ } \\
\text { setembro }\end{array}$ & $\begin{array}{l}\text { Outubro/ } \\
\text { novembro }\end{array}$ & 0,00 \\
\hline Obras e infraestrutura & 0,00 & 0,00 & 0,00 & 0,00 \\
\hline Material permanente & 0,00 & 0,00 & 0,00 & 0,00 \\
\hline Total & 0,00 & 0,00 & 0,00 & \\
\hline
\end{tabular}


Observação: Não há necessidade de a escola adquirir investimento em despesas de capital neste projeto.

\section{Despesas correntes}

\begin{tabular}{|l|l|l|l|l|}
\hline Projeção das Despesa Correntes & $1^{0}$ semestre & $\begin{array}{l}\text { Agosto/ } \\
\text { setembro }\end{array}$ & $\begin{array}{l}\text { Outubro/ } \\
\text { novembro }\end{array}$ & Dezembro \\
\hline Material de Consumo & 473,10 & 630,80 & 2365,50 & 0,00 \\
\hline Papel Ofício A4 & 159,60 & 212,80 & 798,00 & 0,00 \\
\hline Toner & 632,70 & 843,60 & 3163,50 & 0,00 \\
\hline Total & $1^{0}$ semestre & Agosto/ & Outubro/ & Dezembro \\
\hline Serviços de Terceiros & & setembro & novembro & \\
\hline Impressão e gráfica & 0,00 & 0,00 & 0,00 & 1920,00 \\
\hline Encadernações & 0,00 & 0,00 & 0,00 & 1680,20 \\
\hline Serviço de decoração & 0,00 & 0,00 & 0,00 & 1800,00 \\
\hline Total & 0,00 & 0,00 & 0,00 & 5400,20 \\
\hline Total de Despesas & 632,70 & 843,60 & 3163,50 & 10040,00 \\
\hline
\end{tabular}

\section{Detalhamento:}

Papel Ofício A4 - pacote (R\$ 157,70)

Toner - refil $(\mathrm{R} \$ 53,20)$

Serviço de decoração para o lançamento do dicionário

\section{Despesas administrativas e de pessoal}

\begin{tabular}{|l|l|l|l|l|}
\hline \multicolumn{2}{|l|}{ Projeção das Despesa Administrativas e de Pessoal } & Dezembro \\
\hline Administrativas & $1^{0}$ semestre & $\begin{array}{l}\text { Agosto/ } \\
\text { setembro }\end{array}$ & $\begin{array}{l}\text { Outubro/ } \\
\text { novembro }\end{array}$ & 240,00 \\
\hline Luz Elétrica & 720,00 & 240,00 & 0,00 & 120,00 \\
\hline Marketing & 0,00 & 0,00 & 240,00 & 0,00 \\
\hline Total & 720,00 & 240,00 & Outubro/ & 120,00 \\
\hline Pessoal & $1^{0}$ semestre & Agosto/ & Dezembro \\
& & setembro & 1056,00 & 528,00 \\
\hline Professores & 3168,00 & 1056,00 & 15175,00 & 7587,50 \\
\hline Gestores & 45525,00 & 15175,00 & 16231,00 & 8115,50 \\
\hline Total & 48693,00 & 16231,00 & & \\
\hline
\end{tabular}




\section{Dicionário Escolar de Matemática}

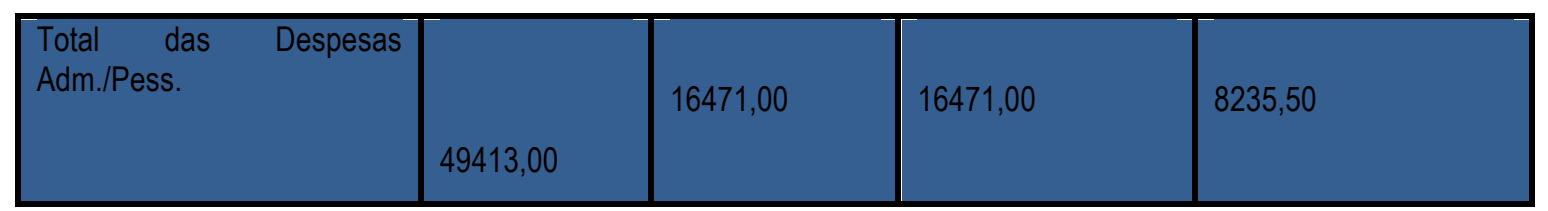

\section{Detalhamento:}

2 professores - 06 horas/aula por semana a $R \$ 11,00$

2 gestores - 40 horas semanais

\section{Necessidades de recursos}

\begin{tabular}{|c|c|c|c|c|c|}
\hline \multicolumn{5}{|l|}{ álculo da Necessidade de Recursos } & \multirow{2}{*}{ TOTAL } \\
\hline !m & $1^{0}$ semestre & $\begin{array}{l}\text { Agosto/ } \\
\text { setembro }\end{array}$ & $\begin{array}{l}\text { Outubro/ } \\
\text { novembro }\end{array}$ & Dezembro & \\
\hline \multicolumn{6}{|l|}{ Total das Despesas Correntes } \\
\hline aterial de Consumo & 632,70 & 843,60 & 3163,50 & 0,00 & 4639,80 \\
\hline 2rviços de Terceiros & 0,00 & 0,00 & 0,00 & 5400,20 & 5400,20 \\
\hline Total de Despesas Administrativas & 720,00 & 240,00 & 240,00 & 120,00 & 1320,00 \\
\hline Total de Despesas com Pessoal & 48693,00 & 16231,00 & 16231,00 & 8115,50 & 89270,50 \\
\hline $\begin{array}{l}\text { Total de Despesas de } \\
\text { ivestimentos) }\end{array}$ & 0,00 & 0,00 & 0,00 & 0,00 & 0,00 \\
\hline כeessidade de Recursos (I+||+|||+|V) & 50045,70 & 17314,60 & 19634,50 & 13635,70 & $100.630,50$ \\
\hline cursos Edital & 0,00 & 4016,00 & 4016,00 & 2008,00 & $10.040,00$ \\
\hline əcursos da Organização (contrapartida) & 49413,00 & 16471,00 & 16471,00 & 8235,50 & $90.590,50$ \\
\hline
\end{tabular}

\section{Detalhamento:}

A equipe conseguiu locar boa parte do muro da escola e obteve um recurso de $R \$ 2.008,00$ mensais no período de agosto a dezembro;

A escola por ser uma entidade estadual recebe os recursos administrativos e de pessoal. 